the native industry. carried on in Madras, Dr. Marsden points out that the difficulties are much more formidable, and he suggests that the first step towards improvement must be the provision of means for the production of indigo of good and uniform quality. One means to this end would be the replacement of small-scale manufacture in nativeowned vats by larger-scale production in well-managed factories, the ryot selling his crop to the factory for manufacture into dyestuff. A possible alternative may be the elaboration of a simple process, capable of being used by the ryot, as the result of the researches now being carried on by $\mathrm{Mr}$. Davis, coupled with some system of analytical control of the produce before shipment.

\section{USES OF INVISIBLE LIGHT IN WARFARE.}

YROF. R. W. WOOD, of Johns Hoplins University, Baltimore, gave to the Physical Society of London on March is a demonstration of the uses of invisible light in warfare. The first device shown was a signalling-lamp, consisting of a 6-volt electric lamp with a small curled-up filament at the focus of a lens of about 3 in. diameter and 12 in. focus. This gave a very narrow beam, only visible in the neighbourhood of the observation post to which the signals were directed. In order to direct the beam in the proper direction, an eyepiece was provided behind the filainent. The instrument was thus converted into a telescope, of which the filament served as graticule. When directed so that the image of the observation post was covered by the filament, the lamp, when lit, threw a beam in the proper direction. In many circumstances the narrowness of the beam was sufficient to ensure secrecy; but sometimes it was not desirable to show any light whatever, and filters were employed to cut out the visible spectrum. By day a deep red filter, transmitting only the extreme red rays, was placed. in front of the lamp. The light was invisible to an observer unless he was provided with a similar red screen to cut out the daylight, in which case he could see enough to read signals at six miles. By night a screen was used which transmitted only the ultra-violet rays. The observing telescope was provided with a fluorescent screen in its focal plane. The range with this was also about six miles. For naval convoy work lamps are required which radiate in all directions. Invisible lamps for this purpose were also designed. In these the radiator was a vertical Cooper-Hewitt mercury arc, surrounded by a chimney of the ultra-violet glass. This glass only transmits one of the mercury lines, viz. $\lambda=3660 \AA$.U., which is quite beyond the visible spectrum. Nevertheless, the lamp is visible at close quarters, appearing of a violet colour, due to fluorescence of the retina. The lens of the eye is also fluorescent. This gives rise to an apparent haze, known as the "lavender fog." which appears to fill the whole field of view. Natural teeth also fluoresce quite brilliantly, but false teeth appear black.

Reverting to the use of the lamps at sea, they are picked up by means of a receiver consisting of a condensing lens in the focal plane of which is a barium-platino-cyanide screen the full diameter of the tube. An eyepiece is mounted on a metal strip across the end of the tube. When the fluorescent spot has once been found somewhere on the screen, it is readily brought to the central part and observed with the evepiece The range is about four miles, and the arrangement has proved invaluable for keeping the shins of a convoy together in their proper relative positions by night.

NO. $258 \mathrm{I}$, VOL. I03]

\section{UNIVERSITY AND EDUCATIONAL} INTELLIGENCE.

LONDON.-A course of eight lectures on "The Physiology of Muscular Exercise" will be given in the Physiological Department, St. Bartholomew's Hospital Medical School, West Smithfield, E.C.I, by Prof. F. A. Bainbridge on Wednesdays at 4.30 p.m., beginning on April 30 . The course is intended for advanced students of the University and others interested in the subject. Admission is free, without ticket.

WE learn from Science that by the will of the late Mr. Morton F. Plant the Connecticut College for Women receives a bequest of $50,000 l$.

Sir Arthur Newsholme has been offered the chair of public health at Johns Hopkins University, Baltimore, and it is understood that he will accept the offer for a year at least.

THE sixth election to Beit fellowships for scientific research will take piace on or about July ${ }^{1} 5$. Not more than three fellowships, of the value of $175 l$. per annum, will be awarded. Applications must be received on or before May $3^{\mathrm{r}}$. Forms of application and all information may be obtained, by letter only, addressed to the Rector, Imperial College, South Kensington, London S.W.7.

By the will of the late Mr. Charles Kerr Marr, the residue of his propertv, amounting apparently to more than $200,000 l$., is left in trust for educational purposes, defined as follows :- " For granting prizes or rewards to persons who are or have been bona-fide residents in the borough of Troon, and who are or have been scholars in some public or elementary school: in or towards building or maintenance of any public school, elementary or otherwise, in Troon; in or towarás the maintenance of exhibitions or scholarships tenable at any institution of education hioher than elementary, as the trustees mav determine. but no exhibition or scholarship shall be awarded to anv person who shall not be or have been a bona-fide resident in Troon."

In the issue for April 5 of the Cologne Post, a daily paper published at Cologne by the Army of the Rhine, is an article on the education of $\mathrm{A}$ iv, boys. The writer states that the boys of eighteen years of age who have been called to the colours recently have, in the majority of cases, proved to be vastly below the standard of education to be expected of boys of that age, as many as 5 per cent. of them being quite illiterate. He goes on to advocate the institution of a system of vocational education while the boys are with the Army of Occupation that will return these lads to their civil occupations each one with his studies completed and with his "apprenticeship" served. The curriculum and time-table of studies sketched in the article indicate a due appreciation of the difficulties of the problem and the possibility of overcoming them successfully.

The Cologne Post of April I publishes an interesting account of the work of the 2 nd Army Agricultural College at Bonn. The object of the college is to provide interesting and useful occupation for our troops during the period preceding demobilisation. Courses were commenced in January, I919, since which time large numbers of soldiers, both officers and other ranks, have received short courses of agricultural instruction. At first the lectures were mainlv theoretical, dealing with agricultural chemistry and botanv, but this was soon altered. and at the present time the students not only have lectures on practical subjects-farm management, etc.--but are also 
able to visit the experimental farms belonging to the University of Bonn, where they see the results of various experiments and actual farm operations. In this way men who are farmers obtain an insight into the scientific principles of their subject, while the novices receive a grounding which will be of value in later years. The students are allowed to use the excellently equipped laboratories of the University, and at weekly meetings students give their agricultural experiences in various parts of the world, and the discussion at these meetings supplies some valuable information.

THE Ministry of Health Bill passed its third reading in the House of Commons on April 9. When before the Standing Committee dealing with the Bill, the measure was, in opposition to the wish of the Government, amended in such a way as to transfer from the Board of Education to the Ministry of Health the responsibility for the medical inspection and treatment of school children. In the House of Commons on April 9, when the Bill returned for further consideration, Dr. Addison proposed to add to it words to the effect that the Minister of Health may make arrangements with the Board of Education respecting the submission and approval of schemes of local education authorities and the payment of grants to these authorities, so far as such schemes and payment relate to or are in respect of medical inspection and treatment; and the powers and duties of the Minister may under any suci arrangements be exercised and performed by the Board on his behalf and with his authority under such conditions as he may think fit. After some discussion, and the insertion of words in the amendment confining its scope to medical inspection and treatment, it was agreed to. In other words, it is now possible for the Mirister of Health. should he so desire, to delegate to the Board of Education those of his powers which have hitherto been administered by the Board.

IN School Hygiene for November last Dr. James Kerr writes on "Congenital or Developmental Aphasia." He points out that although the bibliography on the subject is fairly large, yet little attention has been paid to the theoretical importance and wide bearings of congenital aphasia, when it exists apart from coarse nervous defects. The cases may be conveniently grouped, according to the leading symptom, as graphic and auditory aphasia, of which auditory aphasia, being more fixed by heredity, is less common. Dr. Kerr reviews and criticises the various theories put forward with regard to these cases, and points out that aphasics are sufficiently numerous to warrant more care than they can receive in the ordinary schools. Children who suffer from word-blindness may be highly intelligent in all other respects, and for their best development require special treatment in a children's institute or psychological observational school. Every school population exceeding 100,000 requires some such institute. If the particular brain defect is diagnosed early, many, though not all, are capable of much educational improvement, and the defect so compensated that for practical purposes the individual may be considered normal. If not treated, such childrer tend to swell the numbers in prisons and asvlums.

ThE League for the Promotion of Science in Education, formed by the Committee on the Neglect of Science. which arranged a very successful conference at the Linnean Society in 1916 , is organising another conference, to be held at the Central Hall. Westminster, S.W.. on April 30, at 2.30 p.m. The following resolutions will be submitted to the conference:-(x) That this conference directs attention to the continued neglect of science in the country, and NO. $\left.258 \mathrm{I}, \mathrm{VOL} . \mathrm{IO}_{3}\right]$ calls upon the Government to make immediately such changes in all administrative Departments as shall ensure therein an adequate representation of scientific men. (2) That this conference anxiously awaits a statement on the part of the Government as to the measures it proposes to take to carry out the recommendations set forth in the report of Sir J. J. 'Thomson's Committee on Natural Science in the Educational System of Great Britain. (3) That this conference, whilst fully recognising the value of a literary training, is, nevertheless, of the opinion that the present public school and university system fails to produce that activity of mind and breadth of knowled $\sigma$ e which are essential in a liberal education and necessary for dealing satisfactorily with modern problems. It therefore calls for a closer co-operation between education and industry, and for this purpose emphasises the importance of appointing to headmasterships men of high scientific attainments. No tickets of admission are required, and the Council of the League hopes that there will be a large assembly at the conference to support these resolutions, and thus assist in securing action upon them.

\section{SOCIETIES AND ACADEMIES. \\ LONDON.}

Linnean Society, April 3.--Sir David Prain, president, in the chair.-W. B. Brierley : An albino mutant of Botrytis cinerea, Pers. The fungus Botrytis cinerea possesses characteristic black sclerotia, the solouring matter being deposited in the: walls of the outer two or three layers of cells. Among the black sclerotia in a pedigree culture a single colourless sclerotium was formed, and on isolation this gave rise to a strain characterised by colourless sclerotia. Morphologically and physiologically the parent and mutant strains are identical, and the only difference is the lack of colouring matter in the latter. A generation of the fungus may be obtained in three days, and the two strains tested over very many generations under the most diverse conditions have proved absolutely constant. As the colourless form arose in a "single-spore" culture, it cannot represent a strain selected out from an original population; and as Botrytis cinerea is asexual, the possibility of the new form being a segregant from a heterozygous parent is eliminated. Furthermore, the occurrence of colourless sclerotia in this fungus has heretofore been unknown either in Nature or when the fungus was grown on culture media. There would. therefore, seem no reason to doubt that the colourless form described is an instance of true mutation in the fungus Botrytis cinerea.-Dr. J. D. F Gilchrist: The post-puerulus stage of Jasus lalandii (Milne-Edw.), Ortmann. This paper carried on the investigation already published in the Journal of the Linnean Societv. Zoology (vol. xxxiii., I9I6. pp. Io I-25, pls. I2-I7, with i2 text-figures). as "Larval and Post-Larval Stages of Jasus lalandii." etc. The New Zealand cravfish is now considered to be identical with this Cape species, and found to be of wide distribution. The stage here described is that immediately following the "puerulus" stage; it represents the transition to the adult form. The specimens were obtained by trawling in Table Bay and taken to the marine laboratory at St. James, near Cape Town, where the observations now recorded were made. The author gives minute descriptions, illustrated by drawings similar to those in his previous paper.Dr. H. H. Mann : Variation in flowers of Jasminum malaharicum. Wight. In the forests of the Western Ghats of Bombav, during the month of April, the jungle is covered with flowers of this fragrant and attractive climber. Between April ${ }^{\prime} 3$ and $2 \mathrm{C}$ rgr6, 